\title{
The effect of cigarette prices on brand-switching in China: a longitudinal analysis of data from the ITC China Survey
}

\author{
Justin S White, ${ }^{1}$ Jing Li, ${ }^{1}$ Teh-wei Hu, ${ }^{1}$ Geoffrey T Fong, ${ }^{2,3}$ Yuan Jiang ${ }^{4}$
}

\begin{abstract}
${ }^{1}$ School of Public Health, University of California at Berkeley, Berkeley, California, USA

${ }^{2}$ Department of Psychology, University of Waterloo, Waterloo, Ontario, Canada ${ }^{3}$ Ontario Institute of Cancer Research, Toronto, Ontario, Canada

${ }^{4}$ Office of Tobacco Control, Chinese Centre for Disease Control and Prevention, Beijing, China
\end{abstract}

\section{Correspondence to} Dr Justin S White, School of Public Health, University of California, Berkeley, 247C University Hall, Berkeley, CA 94720, USA:

jswhite@berkeley.edu

Received 1 December 2012 Revised 25 February 2013 Accepted 16 April 2013 Published Online First 22 May 2013
To cite: White JS, Li J, Hu T-wei, et al. Tob Control 2014;23:i54-i60.

\begin{abstract}
Background Recent studies have found that Chinese smokers are relatively unresponsive to cigarette prices. As the Chinese government contemplates higher tobacco taxes, it is important to understand the reasons for this low response. One possible explanation is that smokers buffer themselves from rising cigarette prices by switching to cheaper cigarette brands.
\end{abstract}

Objective This study examines how cigarette prices influence consumers' choices of cigarette brands in China.

Methods This study uses panel data from the first three waves of the International Tobacco Control China Survey, drawn from six large cities in China and collected between 2006 and 2009. The study sample includes 3477 smokers who are present in at least two waves (8552 person-years). Cigarette brands are sorted by price into four tiers, using excise tax categories to determine the cut-off for each tier. The analysis relies on a conditional logit model to identify the relationship between price and brand choice.

Findings Overall, $38 \%$ of smokers switched price tiers from one wave to the next. $A ¥ 1$ change in the price of cigarettes alters the tier choice of $4-7 \%$ of smokers. Restricting the sample to those who chose each given tier at baseline, a $¥ 1$ increase in price in a given tier would decrease the share choosing that tier by $4 \%$ for Tier 1 and $1-2 \%$ for Tiers 2 and 3.

Conclusions China's large price spread across cigarette brands appears to alter the brand selection of some consumers, especially smokers of cheaper brands. Tobacco pricing and tax policy can influence consumers' incentives to switch brands. In particular, whereas ad valorem taxes in a tiered pricing system like China's encourage trading down, specific excise taxes discourage the practice.

\section{INTRODUCTION}

Cigarettes are relatively affordable in China, and their affordability has increased with rising incomes over the last two decades. ${ }^{1}$ Retail data from 2009 (described below) indicate that cigarettes are available in some urban areas for less than $¥ 2$ per pack (approximately US\$ 0.30). Such low-price cigarettes have been identified as a central impediment to smoking cessation. ${ }^{2}{ }^{3}$ A second feature of the cigarette market in China is the considerable variability of prices across brands. The range in prices per pack in Chinese stores routinely vary 10 -fold and in some stores 50 -fold or more. This wide price spread across brands makes it easy for smokers to switch to cheaper cigarettes in China, relative to other countries where the variability of prices is lower.

In the present study, we sought to understand the extent to which cigarette prices alter the purchasing decisions of smokers in China. The answer has profound health and policy implications for China's 300 million smokers.

Research over several decades has established that smokers are sensitive to changes in cigarette prices (eg, Chaloupka and Warner). ${ }^{4}$ The consensus estimate is that, on average-albeit with variation across studies, contexts, empirical specifications and estimation approaches typically falling between -0.2 and $-0.6-$ a $10 \%$ price increase is associated with a $4 \%$ decline in cigarette consumption, implying a price elasticity of $-0.4 .^{5}{ }^{6}$ (See the 2011 International Agency for Research on Cancer report and references therein for more discussion. ${ }^{5}$ ) Yet in China, the price elasticity of demand has been considerably lower, based on analyses of highquality, individual-level data, although some older studies and time series analyses have found tobacco use in China to be more price-elastic. ${ }^{7}$ Lance et al. ${ }^{8}$ find a best estimate of -0.007 in nine Chinese provinces from 1993 to 1997. In an updated analysis, White and $\mathrm{Hu}^{9}$ find similar price insensitivity over the subsequent decade. Mao et al ${ }^{10}$ use national data to estimate a price elasticity estimate of $-0.15 .{ }^{10}$ Huang et al ${ }^{11}$ estimate a price elasticity of consumption (ie, excluding quit behaviour) of -0.13 between 2006 and 2009, using International Tobacco Control (ITC) Survey data. The overall lack of price sensitivity in China raises the public health concern that tobacco tax policy will have little impact on smoking behaviour.

Three potentially overlapping explanations may account for the low observed price elasticity in China. First, prices have changed little over time, and researchers lack sufficient price variation to identify the effect of prices on cigarette demand. Second, rising incomes have outpaced changes in cigarette prices, making cigarettes increasingly affordable over time and making it appear as though smokers do not respond to price changes. Third, the large spread in prices across cigarette brands enables Chinese smokers to buffer themselves against rising cigarette prices by switching to cheaper cigarette brands. Li et al (2011) provide some empirical support for this latter hypothesis by showing that Chinese smokers who buy less-expensive brands tend to be less likely to intend to quit. ${ }^{2}$ In addition, some studies have documented in other contexts an association between cigarette price and type of cigarette 
smoked. ${ }^{12-17}$ Our study provides the first direct test of how price affects smokers' choice of cigarette brands in China. We do so in an empirical framework that also addresses the price variation hypothesis and controls for longitudinal changes in income. Our results highlight how pricing and tax policy in China alter consumers' incentives for choosing one brand over another.

\section{METHODS}

Data

Our data come from the ITC China Survey, a longitudinal survey of smoking behaviour among adults in China. We use the first three panels of the survey data, collected in 2006, 20072008 and 2009 in six capital cities: Beijing, Shanghai, Guangzhou, Shenyang, Changsha and Yinchuan. The ITC China Survey employs a multistage cluster sampling method to obtain a representative sample of adult smokers and non-smokers at the city level. In addition, individual-level sampling weights were constructed to estimate population characteristics. A more detailed description of the methodology of the ITC China Survey is presented in Wu et al. ${ }^{18}$

For the purpose of tracking the same individuals' brand choices at multiple points in time, we restricted the sample to the 4632 continuing smokers who participated in the ITC China Survey for at least two waves. After dropping those smokers for whom the tier choice could not reliably be determined, as discussed below, the final analytical sample included 3477 persons who constituted 8552 person-years (ie, 8552 total observations in the analysis, roughly 2.5 per person). Overall retention in our selected sample is $82.0 \%$ which is relatively high.

\section{Variables}

Dependent variable

The dependent variable was a smoker's choice of cigarette price tier in each wave. Since this information was not readily available in the survey data, we constructed the dependent variable using the brand and price information of cigarettes last purchased by each smoker at the time of survey. Smokers were asked in each wave to provide the brand family, brand variety, total spending and quantity purchased when they last bought cigarettes for themselves, from which we determined the brand and per-pack price of cigarettes. The quantity last purchased is either the number of packs or the number of cartons (equal to 20 packs). Our analysis converts all prices into a per-pack equivalent.

We first validated the price data from the survey against cigarette retail price data collected in the six ITC cities at the same time that Wave 3 was fielded. The retail prices were very similar to average brand-specific prices in the Wave 3 survey data. We compared the city-level median price of the eight most commonly selected brand varieties in the survey data to those varieties' reported retail prices by city, and they were identical for five varieties and differed by less than $¥ 0.5$ for the other three varieties. Next, we assigned to each observation a brand variety code using the ITC Project's classification scheme, based on the Universal Product Code on the barcode of each pack. For cases in which the interviewer entered a name in the 'Other' variety field, we manually assigned a brand variety code based on the names provided by respondents. Through these two routes, we were able to assign a brand variety code to $78 \%$ of all observations involving continuing smokers, which constitutes our final sample. We calculated the median price for each brand variety in each city as the basis for assigning price tiers.
In order to sort brand varieties into price tiers, it is important to use a meaningful, exogenous source of information to determine the cut-off for each tier. We used the six-grade classification of cigarette allocation prices to calculate the retail price range for each grade, which is presented in table 1 . In China, allocation prices are similar to producer prices and serve as the basis for cigarette excise taxes. The allocation prices are drawn from China's State Tobacco Monopoly Administration, as reported in Gao, Zheng and $\mathrm{Hu}$ (2012). ${ }^{19}$ We combined the three most expensive grades into one tier in our analysis because each of those tiers had very few observations. Hence our final classification of cigarette price has four tiers. We assigned a price tier to each observation based on the range into which its by-city median brand variety price falls.

\section{Independent variables}

The independent variable of interest is the nominal price of all tiers from which each smoker chooses. Our analyses depend on relative tier prices; thus, using real prices would have no impact on the analyses. For each tier, we use the median price of all corresponding brand varieties in each city at each wave. Our price measure thus represents the tier-specific market price smokers face in a given city and at a given wave. This measure should be insensitive to any non-systematic bias in smokers' selfreported price.

In addition, we control for a variety of demographic characteristics of smokers: gender, age, income at each wave, education at baseline and average number of cigarettes smoked per day at baseline. Gender, income and education information are coded as categorical variables and enter our model as dummy variables, whereas age and baseline quantity smoked are continuous variables. We also include tier-specific constants and control for the city and wave of each observation. As such, only those factors that vary temporally and geographically may bias our results. We have no evidence that omitted variables such as brand-specific advertising and marketing vary systematically by wave and by city.

\section{Statistical mode}

We employ a conditional logit framework, ${ }^{20}$ which models the probability of a smoker choosing a given tier of cigarettes as a logit function of a linear combination of all independent

Table 1 Cigarette retail prices in China by tier, 2009

\begin{tabular}{llllll}
\hline Tier & $\begin{array}{l}\text { Retail price } \\
\text { (¥/pack) }\end{array}$ & $\begin{array}{l}\text { Producer } \\
\text { profit (\%) }\end{array}$ & $\begin{array}{l}\text { Retail } \\
\text { profit (\%) }\end{array}$ & $\begin{array}{l}\text { Smokers } \\
(\mathrm{N})\end{array}$ & $\begin{array}{l}\text { Smokers } \\
(\%)\end{array}$ \\
\hline 1 & {$[0,2.65)$} & 17.6 & 10.0 & 1114 & 13.2 \\
2 & {$[2.65,5.15)$} & 25.0 & 10.0 & 3830 & 45.3 \\
3 & {$[5.15,8.97)$} & 33.3 & 10.0 & 2345 & 27.7 \\
4 & {$[8.97,18.95)$} & 33.3 & 15.0 & 955 & 11.3 \\
5 & {$[18.95,29.76)$} & 40.8 & 15.0 & 150 & 1.8 \\
6 & {$[29.76, \infty)$} & 51.5 & 15.0 & 59 & 0.7 \\
& & & & 8453 & 100.0 \\
\hline
\end{tabular}

Retail price ranges are calculated according to the formula (Gao, Zheng and $\mathrm{Hu}$, 2011): Retail Price $=$ Allocation Price $\times(1+$ Producer $\pi) \times(1+$ Retail $\pi) \times(1+$ VAT $)$, where $\pi$ denotes profit and VAT is the value-added tax. The ranges for profits come from Gao, Zheng and $\mathrm{Hu}$ (2012). For retail price ranges, a bracket denotes a closed interval, and a parenthesis denotes an open interval. Tiers $4-6$ are combined for analysis due to small cell sizes. Cell counts and proportions are survey weighted. The unweighted sample size is 8552 person-years from 3477 smokers. 
variables:

$$
\operatorname{Pr}\left(\mathrm{Y}_{\mathrm{it}}=\mathrm{k}\right)=\frac{\exp \left(V_{\mathrm{ikt}}\right)}{\sum_{\mathrm{j}=1}^{4} \exp \left(\mathrm{V}_{\mathrm{ijt}}\right)}, \quad \mathrm{k}=1,2,3,4
$$

where

$$
\mathrm{V}_{\mathrm{ijt}}=\alpha \mathrm{P}_{\mathrm{ijt}}+\mathrm{X}_{\mathrm{ijt}} \beta_{\mathrm{j}}
$$

In a given wave $\mathrm{t}$, each smoker $\mathrm{i}$ chooses a price tier $\mathrm{k}$ from $\mathrm{a}$ menu of $\mathrm{j}$ tiers. Smoker i's cigarette tier choice is a logit function of the tier-specific price $\mathrm{P}_{\mathrm{ijt}}$ and a vector of control variables $\mathrm{X}_{\mathrm{ijt}}$, described above. The coefficient of interest is $\alpha$ on tier price.

The conditional logit model differs from a standard logit model in that it allows for inclusion of alternative-specific variables, in this case cigarette prices that vary by tier. The regression includes four different price measures for each smoker, one for each tier, allowing us to take into account the full set of prices each smoker faced in his or her city at a given point in time. In addition to the regression coefficients, the analyses also allows us to estimate the average marginal effects of cigarette tier prices, that is, the change of probability in choosing a given cigarette tier resulting from a $¥ 1$ increase in the median price of that tier. We computed the net marginal effects, accounting for movement in and out of a given tier, and the gross marginal effects, accounting only for movement out of a given tier. The net effects were calculated from the full sample, whereas the gross effects were calculated separately for each tier by restricting the sample to those smokers who used a given tier at baseline (ie, in the earliest wave in which the smoker appeared in the sample). We computed bootstrapped standard errors for the average marginal effects, using 1000 repetitions and clustering at the individual level.

\section{RESULTS}

\section{Descriptive statistics}

Table 1 shows the retail price ranges associated with each cigarette tier. About $45 \%$ of smokers chose a brand that falls in the second-cheapest tier (roughly $¥ 3$ - $¥ 5$ per pack). The next most commonly selected is the third-cheapest tier (28\%, ¥5- ¥9), fol-

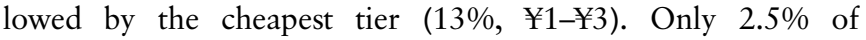
smokers last bought a pack in one of the two most expensive tiers, in which cigarettes cost more than $¥ 19$. Retail prices are derived from government-regulated profit rates for producers and retailers. Allowable profit rates vary by tier, such that more expensive packs yield greater returns.

Figure 1 shows the degree to which smokers switch cigarette tiers across waves. A majority of smokers, between $50 \%$ and $71 \%$ depending on the tier and waves under consideration, stayed within the same price tier from wave to wave, yet a sizeable fraction switch cigarette tiers over time. Overall, 38\% of smokers switched tiers from one survey round to the next. For mid-priced tiers (Tiers 2 and 3), in which a smoker could choose a more or less expensive brand, trading up to a more expensive tier tended to be more common than trading down. An exception is Tier 3 users in Wave 2, who were more likely to trade down in Wave 3. The general pattern of trading up may reflect that incomes rose faster than cigarette prices during this time period, providing cigarette users with additional purchasing power. Whereas tobacco prices increased a mere 1.5\% nationally from 2006 to 2009 , according to the official statistics from the tobacco consumer price index, ${ }^{21}$ average nominal incomes for urban residents rose $46 \%$ during this time period. ${ }^{23}$

According to the descriptive statistics presented in table 2, more than $96 \%$ of the sample is men. The average age of smokers is 51 years. The average price of cigarettes purchased is $¥ 6.32$ and the median price (not shown) is $¥ 5.00$. Average nominal and real cigarette prices in 2006 terms are nearly identical, due to very low growth in the consumer price index for tobacco products during this time period. On average, sample respondents smoked 18 cigarettes, or slightly less than one full pack, per day. A plurality of smokers (46\%) had a monthly household income between $¥ 1000$ and $¥ 3000$ (US\$150 to US $\$ 450)$. About a third of the study sample had a junior high school education, about a third had a high school education, and the remainder was split between a primary or tertiary education.

\section{MULTIVARIATE RESULTS}

The main study results are based on a conditional logit regression of cigarette tier prices on tier choice, controlling for wave, city, sex, age, income, education and baseline cigarette intake. Table 3 shows the results of this regression. Own-tier price has a statistically significant negative effect on a smoker's choice of that tier. We consider the magnitude of the price effects in further detail below. Older smokers are significantly more likely to choose cheaper tiers. Smokers with low socioeconomic status 一those with low income (below $¥ 1000$ ) or low education (primary school or less)—are significantly more likely to buy from the cheapest tier, and, similarly, the probability of choosing a higher-priced tier increases with socioeconomic status. Baseline cigarette consumption is not consistently associated with tier choice, although the probability of choosing Tier 2 decreases with baseline consumption. Relative to smokers in Beijing, those in Shanghai and Guangzhou consistently have a greater likelihood of selecting a higher-priced tier (Tiers 2-4).

The magnitude of the average marginal effect of price on tier choice is described in table 4. Panel A includes the net marginal price effects of moving in and out of a given tier, and Panel B includes the gross marginal price effects of moving out of a tier for those smokers who chose that given tier in Wave 1 .

We start by describing the net price effects and then describe the gross price effects. If the price of Tier- 1 cigarettes rose $¥ 1$, then the net change in the probability of choosing Tier- 1 cigarettes would decrease by $0.9 \%$ points (ie, a negative own-price effect) and the net change in the probability of choosing other tiers would increase (ie, a positive cross-price effect). Similarly, the average net own-price effects for Tiers 2-4 correspond to declines in the probability of using each respective tier by $1.9 \%$ points, $1.5 \%$ points and $0.9 \%$ points. A $¥ 1$ increase corresponds to a $20 \%$ increase in the overall median cigarette price in our sample ( $¥ 5$ ). Whereas on net trading up to a more expensive tier is more likely than downtrading among Tier- 2 smokers, the reverse is true for Tier-3 smokers. In addition, we use the share of smokers within each tier (second-to-last row in Panel A of table 4) to interpret the percentage change in the share choosing each tier as implied by that tier's net own-price effect (last row in Panel A of table 4). Dividing the net own-price effect for a given tier by the share of smokers within that tier, we calculate that $¥ 1$ increase translates roughly into a $4-7 \%$ decrease in the net share choosing that tier, depending on the starting tier. The largest behavioural effects occur among smokers in the cheapest and the most expensive tiers.

The gross effect of tier-switching among those who used a given tier at baseline follows a similar pattern, although the 
Figure 1 Percentage of smokers switching tiers between consecutive waves. Note: Column percentages are shown. (A) Displays switching from Wave 1 to Wave 2 among 2474 smokers. (B) Displays switching from Wave 2 to Wave 3 among 2240 smokers. (a) Wave 1 to Wave 2

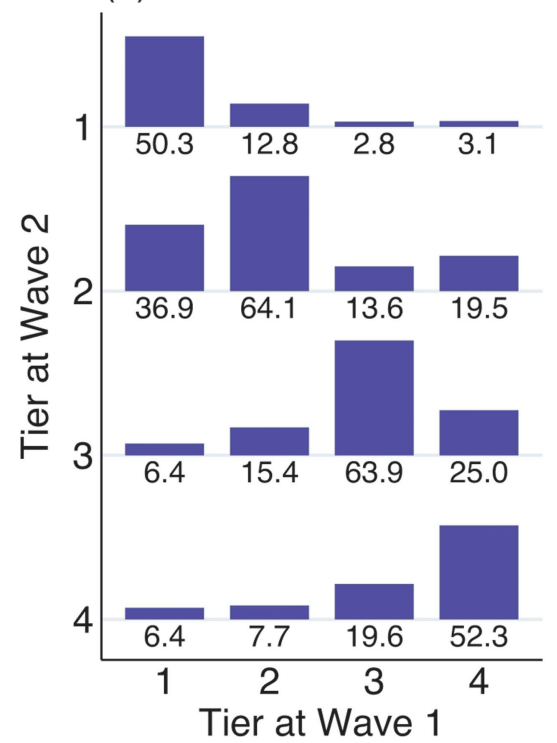

(b) Wave 2 to Wave 3

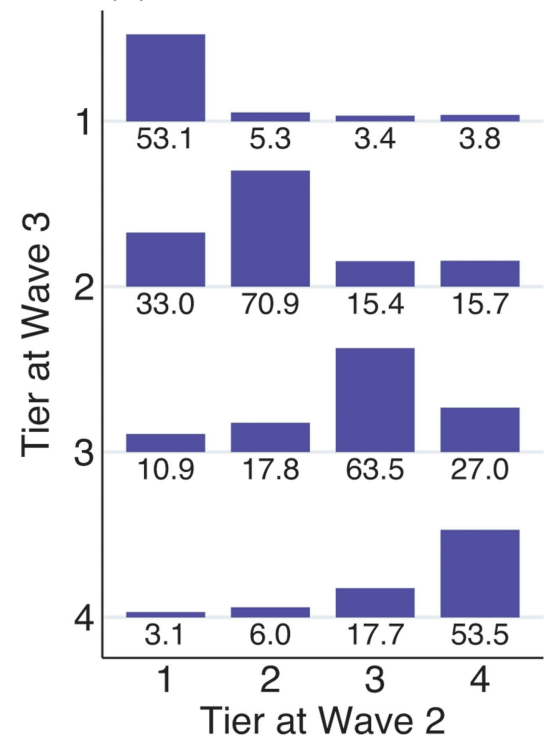

magnitude of the marginal effects varies somewhat between the net and gross effects. If the price of Tier- 1 cigarettes rose by $¥ 1$, then smokers of Tier-1 cigarettes would be $4.1 \%$ points less likely to choose Tier 1 in subsequent waves. The gross ownprice effects for Tiers 2 and 3 are about $0.6 \%$ points and $1.7 \%$ points. In other words, Tier-1 smokers are most likely to respond to the $¥ 1$ price change. This is consistent with the fact that $¥ 1$ represents a larger relative price change for a pack of inexpensive cigarettes from Tier 1 than for a pack of more

Table 2 Descriptive statistics, 2006-2009

\begin{tabular}{|c|c|c|}
\hline Variable description & Mean & SD \\
\hline \multicolumn{3}{|l|}{ Binary variables } \\
\hline Male & 0.963 & - \\
\hline Monthly household income: $<¥ 1000$ & 0.161 & - \\
\hline Monthly household income: $¥ 1000-2999$ & 0.464 & - \\
\hline Monthly household income: $¥ 3000-4999$ & 0.240 & - \\
\hline Monthly household income: $\geq ¥ 5000$ & 0.134 & - \\
\hline Education: Primary school or less & 0.125 & - \\
\hline Education: Middle school & 0.327 & - \\
\hline Education: High school & 0.358 & - \\
\hline Education: Beyond secondary school & 0.190 & - \\
\hline Wave 1 (2006) & 0.332 & - \\
\hline Wave 2 (2007-08) & 0.365 & - \\
\hline Wave 3 (2009) & 0.303 & - \\
\hline City: Beijing & 0.172 & - \\
\hline City: Shenyang & 0.138 & - \\
\hline City: Shanghai & 0.224 & - \\
\hline City: Changsha & 0.185 & - \\
\hline City: Guangzhou & 0.142 & - \\
\hline City: Yinchuan & 0.139 & - \\
\hline \multicolumn{3}{|l|}{ Continuous variables } \\
\hline Age at Wave 1 & 50.8 & 12.3 \\
\hline Cigarette tier price, nominal & 6.32 & 6.36 \\
\hline Cigarette tier price, real, in 2006 terms & 6.24 & 6.30 \\
\hline Average daily cigarette consumption at Wave 1 & 17.7 & 10.8 \\
\hline
\end{tabular}

expensive cigarettes from Tier 3 . The added price sensitivity for Tier 1 holds when we look at how large this price effect is relative to the share of starting smokers in each tier (second-to-last row of Panel B in table 4). The $¥ 1$ increase translates into a $4 \%$ decrease in the gross share choosing Tier 1, compared with a 1$2 \%$ decrease for Tier- 2 and Tier-3 smokers. Trading up is more common for Tier-2 smokers, similar to the net effects, whereas trading up and down appears to be equally common for the Tier-3 smokers.

We ran several sensitivity analyses to validate the association between price and tier choice (results not shown). We find some evidence that the relationship is not attributable to use of smuggled cigarettes. Among the subgroup of smokers who provided to the survey enumerators a pack with an authenticity label, which we assume to be indicative of a legally purchased pack, the price coefficient is of similar magnitude $(-0.087)$ and statistically indistinguishable from the full sample $(p=0.61)$. The similarity between survey and retail price data also provides some suggestive evidence that smuggling and counterfeiting are not major concerns in our sample, because illicit tobacco use should lead the mean survey price to diverge from retail survey prices, which we do not find. The choice of sample composition -those individuals present in two or more waves-also did not affect the magnitude of the effect. Placing no restrictions on those included in the analysis $(n=10020)$, the price coefficient is -0.075 , insignificantly different from the restricted sample $(\mathrm{p}=0.17)$. Likewise, restricting the sample to those present in all three waves $(n=4839)$ yields a price coefficient of -0.086 , also insignificantly different from our final sample $(p=0.64)$,

\section{DISCUSSION}

Nearly $40 \%$ of smokers in our sample switched tiers across survey rounds, indicating that consumers are relatively flexible in brand choices and do not display strong loyalty to one brand variety. Brand choice appears to be sensitive to the price of cigarettes, controlling for each smoker's income and several other sociodemographic characteristics. We find that a ¥1 increase in the median price of a given tier would lead $4-7 \%$ fewer smokers to select that given tier, combining the net effect of smokers moving into and out of that tier. Isolating the gross effect of a $¥ 1$ increase in the median price of a given tier on the 
Table 3 Regression results from conditional logit model

\begin{tabular}{|c|c|c|c|c|}
\hline & $\begin{array}{l}\text { No } \\
\text { interaction }\end{array}$ & $\begin{array}{l}\text { Interacted } \\
\text { with Tier } \\
2\end{array}$ & $\begin{array}{l}\text { Interacted } \\
\text { with Tier } \\
3\end{array}$ & $\begin{array}{l}\text { Interacted } \\
\text { with Tier } \\
4\end{array}$ \\
\hline Cigarette tier price & $\begin{array}{l}-0.095^{* * *} \\
(0.015)\end{array}$ & & & \\
\hline Male & & $\begin{array}{l}0.653^{* * *} \\
(0.177)\end{array}$ & $\begin{array}{l}0.717^{* * *} \\
(0.264)\end{array}$ & $\begin{array}{l}0.847^{* *} \\
(0.420)\end{array}$ \\
\hline Age & & $\begin{array}{l}-0.031^{* * *} \\
(0.006)\end{array}$ & $\begin{array}{l}-0.060^{* * *} \\
(0.006)\end{array}$ & $\begin{array}{l}-0.068^{* * *} \\
(0.007)\end{array}$ \\
\hline Income: ¥1000-2999 & & $\begin{array}{l}0.503^{* * *} \\
(0.114)\end{array}$ & $\begin{array}{l}1.086^{* * *} \\
(0.152)\end{array}$ & $\begin{array}{l}0.931^{* * *} \\
(0.193)\end{array}$ \\
\hline Income: ¥3000-4999 & & $\begin{array}{l}0.757^{* * *} \\
(0.167)\end{array}$ & $\begin{array}{l}1.872^{* * *} \\
(0.203)\end{array}$ & $\begin{array}{l}2.010^{* * *} \\
(0.238)\end{array}$ \\
\hline Income: $\geq ¥ 5000$ & & $\begin{array}{l}1.183^{* * *} \\
(0.239)\end{array}$ & $\begin{array}{l}2.483^{* * *} \\
(0.263)\end{array}$ & $\begin{array}{l}3.073^{* * *} \\
(0.295)\end{array}$ \\
\hline Education: Middle school & & $\begin{array}{l}0.467^{* * *} \\
(0.168)\end{array}$ & $\begin{array}{l}0.658^{* * *} \\
(0.199)\end{array}$ & $\begin{array}{l}0.430^{*} \\
(0.243)\end{array}$ \\
\hline Education: High school & & $\begin{array}{l}0.545^{* * *} \\
(0.174)\end{array}$ & $\begin{array}{l}0.975^{* * *} \\
(0.206)\end{array}$ & $\begin{array}{l}0.981^{* * *} \\
(0.237)\end{array}$ \\
\hline $\begin{array}{l}\text { Education: Beyond } \\
\text { secondary }\end{array}$ & & $\begin{array}{l}0.879^{* * *} \\
(0.218)\end{array}$ & $\begin{array}{l}1.511^{* * *} \\
(0.258)\end{array}$ & $\begin{array}{l}1.747^{* * *} \\
(0.282)\end{array}$ \\
\hline $\begin{array}{l}\text { Cigarette consumption } \\
\text { at Wave } 1\end{array}$ & & $\begin{array}{l}-0.006 \\
(0.005)\end{array}$ & $\begin{array}{l}-0.143^{* *} \\
(0.006)\end{array}$ & $\begin{array}{l}-0.009 \\
(0.007)\end{array}$ \\
\hline Wave 2 & & $\begin{array}{l}-0.165 \\
(0.101)\end{array}$ & $\begin{array}{l}-0.034 \\
(0.113)\end{array}$ & $\begin{array}{l}0.197 \\
(0.133)\end{array}$ \\
\hline Wave 3 & & $\begin{array}{l}0.006 \\
(0.113)\end{array}$ & $\begin{array}{l}0.242^{*} \\
(0.134)\end{array}$ & $\begin{array}{l}0.645^{* * *} \\
(0.147)\end{array}$ \\
\hline City: Shenyang & & $\begin{array}{l}-0.186 \\
(0.180)\end{array}$ & $\begin{array}{l}-0.081 \\
(0.209)\end{array}$ & $\begin{array}{l}1.426^{* * *} \\
(0.303)\end{array}$ \\
\hline City: Shanghai & & $\begin{array}{l}0.993^{* * *} \\
(0.271)\end{array}$ & $\begin{array}{l}3.462^{* * *} \\
(0.274)\end{array}$ & $\begin{array}{l}4.502^{* * *} \\
(0.363)\end{array}$ \\
\hline City: Changsha & & $\begin{array}{l}1.257^{* * *} \\
(0.197)\end{array}$ & $\begin{array}{l}0.336 \\
(0.236)\end{array}$ & $\begin{array}{l}2.866^{* * *} \\
(0.311)\end{array}$ \\
\hline City: Guangzhou & & $\begin{array}{l}0.644^{* * *} \\
(0.208)\end{array}$ & $\begin{array}{l}1.810^{* * *} \\
(0.225)\end{array}$ & $\begin{array}{l}1.454^{* * *} \\
(0.358)\end{array}$ \\
\hline City: Yinchuan & & $\begin{array}{l}1.244^{* * *} \\
(0.207)\end{array}$ & $\begin{array}{l}0.459^{*} \\
(0.249)\end{array}$ & $\begin{array}{l}2.942^{* * *} \\
(0.314)\end{array}$ \\
\hline Constant & & $\begin{array}{l}1.235^{* * *} \\
(0.442)\end{array}$ & $\begin{array}{l}0.832 \\
(0.539)\end{array}$ & $\begin{array}{l}-0.828 \\
(0.637)\end{array}$ \\
\hline Number of persons & 3477 & & & \\
\hline Number of person-years & 8552 & & & \\
\hline Number of observations & 34208 & & & \\
\hline
\end{tabular}

Robust standard errors, in parentheses, are clustered at the person level and weighted for survey sampling. The omitted category for categorical variables is: income below $¥ 1000$, primary education and below, Wave 1 and Beijing. The mode includes tier-specific constants.

Statistical significance: ${ }^{*} p<0.10{ }^{* *} p<0.05{ }^{* * *} p<0.01$.

probability of moving out of that tier, smokers who use cigarettes from the cheapest Tier 1 would be $4 \%$ less likely to select Tier 1 cigarettes following the price increase, whereas smokers of Tier- 2 or Tier- 3 cigarettes at Wave 1 would be only $1-2 \%$ less likely to select their starting tier. Thus, users of cheap cigarettes appear to be more sensitive to price increases when selecting a cigarette brand. To the extent that consumers can trade down to a cheaper brand while remaining within the same tier, our estimates may understate the degree to which price drives brand-switching. Overall, our findings underscore the role that tobacco pricing and tax policies can play in a consumer's brand decision and the degree to which consumers strategically switch brands.

The Chinese government influences retail cigarette prices by regulating their four constituent parts: the tax base (the allocation price), the value-added tax, profit margins for wholesalers and profit margins for retailers. ${ }^{19}$ Current pricing regulations (of profit margins) may inadvertently promote downtrading to cheaper cigarettes among consumers. China permits more lucrative profit margins to wholesalers and retailers of higher-priced cigarettes than for lower-priced cigarettes (table 1). These incentives likely contribute to China's large price spread. More importantly, if cigarette manufacturers and retailers are able to stimulate demand for higher-priced cigarettes through advertising and special promotions, then these practices facilitate the ability of smokers to trade down to cheaper cigarettes in times of economic hardship.

China's tax policy is a direct contributor to consumers' choice of cigarette brands. In China, cigarette taxes as a percentage of retail prices have held steady at roughly $40 \%$ in recent years ${ }^{24}$ compared with the World Health Organization's recommended benchmark of $70 \% .^{24}$ Low excise taxes on cigarettes mean that consumers feel little financial pressure to reduce tobacco expenditures by quitting smoking. Rather, smokers have the ability to purchase cheap cigarettes. The composition of cigarette taxes is perhaps more important for brand-switching than the level of taxation. In particular, ad valorem taxes (assessed as a percentage of price) and specific taxes (assessed as a fixed amount per unit) have different effects on the incentives for consumers to choose relatively less expensive brands. An increase in a uniform ad valorem tax rate would leave unchanged the relative prices across tiers while increasing the absolute price difference. Since relative prices determine resource allocation in standard microeconomic theory, a uniform increase would not alter the gains to trading down to a cheaper brand. However, in China's tiered tax system, an increase in the ad valorem tax would increase the absolute price spread and the relative prices across tiers, effectively increasing the payoff to trading down to a cheaper brand. One would expect the probability of downtrading to increase with the payoff. Moreover, China's unusually large price spread for cigarettes serves as a positive moderator of the impact of ad valorem taxes, accentuating the payoff to downtrading. In contrast, a specific tax shrinks the per cent variance across tiers, reducing the payoff to switching to a relatively cheaper brand. Specific excise taxes are superior to ad valorem taxes in reducing the absolute share of cheap cigarettes that are available in a given market, likely reducing the degree to which consumers trade down and likely increasing the extent to which a tax increase induces consumers to quit smoking. These features of specific taxes are key to why experts have advocated a reliance on specific tobacco taxation. ${ }^{24}$

The current excise tax structure in China includes specific and ad valorem taxes. ${ }^{7}$ However, the specific tax is a mere $¥ 0.06$ per pack. In May 2009, China’s State Tobacco Monopoly Administration officially raised the ad valorem tax rates to $56 \%$ of allocation prices for packs that have an allocation price of $¥ 7$ or more, $36 \%$ on those costing less than $¥ 7$ and an additional $5 \%$ tax applied to the wholesale price. However, the government directed the tobacco industry to absorb the tax increase, leaving retail prices unchanged. ${ }^{11}$ Thus, the tax rates felt by consumers are far less than official rates indicate. Overall, China's tax structure does little to deter downtrading and may promote it through its reliance on ad valorem taxation. 
Table 4 Average marginal price effects on switching tiers

\begin{tabular}{|c|c|c|c|c|}
\hline & Tier 1 & Tier 2 & Tier 3 & Tier 4 \\
\hline \multicolumn{5}{|l|}{ Panel A. Net effects } \\
\hline \multirow[t]{2}{*}{ Median Tier-1 price } & -0.890 & 0.640 & 0.200 & 0.070 \\
\hline & $(0.012)$ & $(0.010)$ & $(0.003)$ & $(0.001)$ \\
\hline \multirow[t]{2}{*}{ Median Tier-2 price } & 0.622 & -1.943 & 0.857 & 0.426 \\
\hline & $(0.010)$ & $(0.009)$ & $(0.008)$ & $(0.006)$ \\
\hline \multirow[t]{2}{*}{ Median Tier-3 price } & 0.198 & 0.866 & -1.515 & 0.450 \\
\hline & $(0.003)$ & $(0.008)$ & $(0.013)$ & $(0.010)$ \\
\hline \multirow[t]{2}{*}{ Median Tier-4 price } & 0.071 & 0.437 & 0.458 & -0.946 \\
\hline & $(0.001)$ & $(0.006)$ & $(0.010)$ & $(0.011)$ \\
\hline Number of person-year observations & 8552 & 8552 & 8552 & 8552 \\
\hline Share of observations in Tier k & $12.64 \%$ & $44.68 \%$ & $28.70 \%$ & $13.99 \%$ \\
\hline$\%$ change in share choosing Tier k, implied by net own-price effect & $-7.04 \%$ & $-4.35 \%$ & $-5.28 \%$ & $-6.76 \%$ \\
\hline \multicolumn{5}{|l|}{ Panel B. Gross effects } \\
\hline \multirow[t]{2}{*}{ Median Tier-1 price } & -4.050 & 0.169 & 0.154 & - \\
\hline & $(0.056)$ & $(0.004)$ & $(0.005)$ & \\
\hline \multirow[t]{2}{*}{ Median Tier-2 price } & 2.775 & -0.552 & 0.672 & - \\
\hline & $(0.048)$ & $(0.006)$ & $(0.016)$ & \\
\hline \multirow[t]{2}{*}{ Median Tier-3 price } & 0.800 & 0.265 & -1.676 & - \\
\hline & $(0.028)$ & $(0.004)$ & $(0.019)$ & \\
\hline \multirow[t]{2}{*}{ Median Tier-4 price } & 0.474 & 0.118 & 0.850 & - \\
\hline & $(0.020)$ & $(0.003)$ & $(0.015)$ & \\
\hline Number of person-year observations & 1236 & 4206 & 2522 & - \\
\hline Share of observations starting in Tier $k$ & $100.0 \%$ & $100.0 \%$ & $100.0 \%$ & - \\
\hline$\%$ change in share choosing Tier $k$, implied by gross own-price effect & $-4.05 \%$ & $-0.55 \%$ & $-1.68 \%$ & - \\
\hline
\end{tabular}

Public health experts have encouraged the Chinese government to raise tobacco taxes as a way to increase cigarette prices and curb smoking rates. ${ }^{25}$ Over the coming years, China is expected to follow these recommendations, in conjunction with its obligations under Article 6 of the Framework Convention on Tobacco Control, which covers price and tax measures for reducing the demand for tobacco products. Our study indicates that the design of the tax-namely ad valorem versus specific-will affect how consumers respond to the tax. The exact impact is difficult to quantify. Downtrading diminishes the price elasticity of demand to the extent that consumers' counterfactual response to the tax hike, in the absence of an ability to trade down, would be to quit smoking. In order to estimate the effect of a tax on consumer behaviour with and without downtrading, one would need to make assumptions about (1) the share of consumers who would smoke if allowed to trade down and who would quit otherwise, (2) the size and type of tax being imposed and (3) the differential impact of specific and ad valorem taxes on trading down. Our study can inform this third assumption, but we are not aware of any existing studies that address the probability of quitting under scenarios with and without downtrading. It is a topic worthy of future research.

Our study has several limitations. First, we characterised the degree of brand substitution across tiers, but we were unable to explore brand-switching within tiers. Second, we relied on selfreported prices, which could suffer from reporting bias (eg, under-reporting the price due to use of illicit cigarettes). However, the similarity between self-reported and retail prices offers some evidence that any bias is likely to be small. Finally, our analyses do not take into account heterogeneity in smokers' preferences (eg, by education and income category), although it is an area we plan to pursue in future research.

\section{What this paper adds}

- China's government is widely expected to raise cigarette tax rates in the next decade, but how Chinese consumers will respond to a cigarette price increase is not well understood.

- This paper describes for the first time how cigarette prices have influenced the cigarette brand choice of Chinese smokers.

- The discrete choice methodology offers a rigorous approach for identifying the impact of cigarette prices on purchasing behaviour.

Acknowledgements We thank Qiang Li for access to the retail price data and Anne Chiew Kin Quah for administrative support. We also thank Frank Chaloupka for helpful comments and suggestions. All errors are our own.

Contributors JSW conceived and designed the study, analysed the data, interpreted the results, and drafted the manuscript. JL analysed the data, interpreted the results, and drafted the manuscript. TH conceived and designed the study and contributed to revisions of the manuscript. GTF supervised data collection and commented on an earlier draft of the manuscript. JY supervised data collection. All authors reviewed and approved the final manuscript. The corresponding author had full access to all data and final responsibility for the decision to submit the report for publication.

Funding JSW was supported by a grant from the US National Institute on Aging (T32-AG000246). TH was supported by a grant from the US Fogarty International 
Center (R01-TW05938). GTF was supported by a Senior Investigator Award from the Ontario Institute for Cancer Research and by a Prevention Scientist Award from the Canadian Cancer Society Research Institute. The ITC China Project was supported by grants from the US National Cancer Institute (R01-CA125116 and P01-CA138389), the Roswell Park Transdisciplinary Tobacco Use Research Center (P50-CA111236), the Canadian Institutes of Health Research (57897, 79551 and 115016), and the Chinese Center for Disease Control and Prevention.

\section{Competing interests None.}

Patient consent Obtained.

Ethics approval The ITC China Surveys were cleared for ethics by Research Ethics Boards or International Review Boards at the University of Waterloo (Canada), Roswell Park Cancer Institute (USA), and the Chinese Center of Disease Control and Prevention.

Provenance and peer review Not commissioned; externally peer reviewed.

\section{REFERENCES}

1 Blecher EH, van Walbeek CP. Cigarette affordability trends: an update and some methodological comments. Tob Control 2009;18:167-75.

2 Li Q, Hyland A, Fong GT, et al. Use of less expensive cigarettes in six cities in China: Findings from the International Tobacco Control (ITC) China Survey. Tob Control 2011;19:i63-8.

3 Hyland A, Hibee C, Li Q, et al. Access to low-taxed cigarettes deters smoking cessation attempts. Am J Public Health 2005;95:994-5.

4 Chaloupka FJ, Warner KE. The economics of smoking. In: Culyer AJ, Newhouse JP, eds. Handbook of health economics. Vol. 1. 2000:1539-627.

5 International Agency for Research on Cancer. Effectiveness of tax and price policies for tobacco control. Chapter 5. Lyon, France: International Agency for Research on Cancer. 2011:137-200.

6 Gallet CA, List JA. Cigarette demand: a meta-analysis of elasticities. Health Econ 2003; 12:821-35

7 Hu T, Mao Z, Shi J, et al. Tobacco taxation and its potential impact in China. Paris: International Union Against Tuberculosis and Lung Disease, 2008.

8 Lance PM, Akin JS, Dow WH, et al. Is cigarette smoking in poorer nations highly sensitive to price? Evidence from Russia and China. J Health Econ 2004;23:173-89.

9 White JS, Hu T. How do Chinese smokers respond to changes in cigarette prices? Unpublished working paper. 2012.
10 Mao Z, Sung HY, Hu TW, et al. The demand for cigarettes in China. Chapter 7. In: Hu TW, ed. Tobacco Control Policy Analysis in China. Hackensack, NJ: World Scientific Publishing Co., 2008:129-57.

11 Huang J, Zheng R, Chaloupka F, et al. Price Responsiveness among Chinese Urban Adult Smokers: Findings from the ITC China Survey. Presentation at World Conference on Tobacco or Health. Singapore, 2012.

12 Evans WN, Farrelly MC. The compensating behavior of smokers: Taxes, tar, and nicotine. RAND J Econ 1998:29:578-95.

13 Tsai YW, Yange CL, Chen CS, et al. The effect of Taiwan's tax-induced increases in cigarette prices on brand-switching and the consumption of cigarettes. Health Econ 2005; 14:627-41.

14 Hanewinkel R, Radden C, Rosenkranz T. Price increase causes fewer sales of factory-made cigarettes and higher sales of cheaper loose tobacco in Germany. Health Econ 2008;17:683-93.

15 Ohsfeldt RL, Boyle RG, Capilouto E. Effects of tobacco excise taxes on the use of smokeless tobacco products in the USA. Health Econ 1997:6:525-31.

16 Wangen KR, Biørn E. How do consumers switch between close substitutes when price variation is small? The case of cigarette types. Spanish Economics Review 2006:8:239-53.

17 White JS, Ross H. Do Smokers Undermine the Health Goals of Cigarette Taxes? Unpublished working paper. 2013.

18 Wu C, Thompson ME, Fong GT, et al. Methods of the International Tobacco Contro (ITC) China Survey. Tob Control 2010;19:i1-5.

19 Gao A, Zheng R, Hu TW. Can increases in the cigarette tax rate be linked to cigarette retail prices? Solving mysteries related to the cigarette pricing mechanism in China. Tob Control 2012;21:560-2.

20 McFadden D. Conditional logit analysis of qualitative choice behavior. In: Zarembka P, ed. Frontiers in Econometrics. New York, NY: Academic Press 1973;105-42.

21 National Bureau of Statistics of China (2012a). Tobacco Consumer Price Index, 2006-2009. http://www.stats.gov.cn/tjsj/ (accessed 26 Nov 2012)

22 National Bureau of Statistics of China (2012b). Import Urban Resident Income Data 2006-2009. http://www.stats.gov.cn/tjsj/ (accessed 26 Nov 2012)

$23 \mathrm{Hu}$ T, Mao Z, Shi J. Recent tobacco tax rate adjustment and its potential impact on tobacco control in China. Tob Control 2010;19:80-2.

24 World Health Organization. WHO Technical Manual on Tobacco Tax Administration. Geneva, Switzerland, 2011.

25 World Health Organization. WHO Supports Increasing Prices for Tobacco in China. 2012. Press Release. http://www2.wpro.who.int/china/media_centre/press_releases/ PR_20120314.htm/ (accessed 21 Apr 2012). 